\title{
HIGHER STAGE DEVELOPMENT OF A FUZZY PI CONTROLLER FOR A GRID CONNECTED WIND ENERGY AND CONVERSION SYSTEM
}

\author{
Anshul Trivedi ${ }^{1}$, Kamlesh Singh $^{2}$, Ashutosh Kumar Singh ${ }^{3}$, Akash Shukla $^{4}$ \\ ${ }^{1}$ Ambalika Institute of Management and Technology, Lucknow, U.P.,India \\ ${ }^{2}$ Ambalika Institute of Management and Technology, Lucknow, U.P.,India \\ ${ }^{3}$ Ambalika Institute of Management and Technology, Lucknow, U.P.,India \\ ${ }^{4}$ Ambalika Institute of Management and Technology, Lucknow, U.P.,India
}

\begin{abstract}
In recent years power generation from renewable energy sources has gained importance in view of supplementing the power obtained from conventional sources. Out of all the renewable energy sources, wind energy conversion system is the greatest contributor to the power generations. During the recent years use of variable speed of the wind turbine is gaining much more importance than the fixed speed wind turbine. Important factors regarding variable speed operation are that it is easy to control and is even more efficient. Therefore, it is important to study the machine modelling of the double fed induction generator (DFIG) for a wind energy conversion system (WECS). One of the major areas in renewable power control includes the grid connected DFIG based WECS. Typically a DFIG based WECS consists of a Wind turbine connected to a DFIG and then the turbine-coupled DFIG is connected to the grid through a power electronic AC-AC converter.
\end{abstract}

In this Paper a grid connected wind energy conversion system using a simple PI controller is developed and then a fuzzy PI controller is designed to resolve the problem. Finally a comparison has been made to fuzzy controller from the simulation results, observing the efficiency of variation of DC link voltage variation.

\section{INTRODUCTION}

It is quite accepted that the earth ${ }^{\text {ee }}$ fossil energy resources are limited, and the cost of global oil, coal and gas production continues to rise beyond their peak. Fossil fuels belong to finite sources and so will be completely exhausted one day or the other. Comparing to the above case renewable energies have been in a great demand due to absence of the emissions of poisonous gases like carbon dioxide and sulphur dioxide. The various types of renewable energy sources contributing to current energy demand consist of water, wind, solar energy and biomass. However the major drawback suffered by hydroelectric power plants is its expensive and costly nature to build and also the plants must operate for a long time to become profitable. The creation of dams may even lead to flooding of lands leading to environmental destruction. Similarly solar energy can only be extracted from solar thermal collectors in the presence of sunlight.Due to this condition solar energy set up becomes impractical in areas where there is littile sunlight or heavy rainfall.

The increasing development of wind energy has resulted in many new modeling and improved simulationmethods. Wind power harnessing procedure has been a task for many years. Since long back wind mills were put into the task of pumping water and grinding grain. Many new technologiessuch as pitch control and variable speed control methods have been tested and put forward since. Sometimes, wind turbine work in an isolating mode; therefore, there is no grid. Usually there aretwo, three or even more than three blades on a wind turbine. However according toaerodynamics concept, three blades is the optimum number of blades for a wind turbine.Asynchronous and synchronous ac machines are the main generators that are used in the windturbines. A wind turbine extracts kinetic energy from the wind and converts this into mechanicalenergy. Finally, this mechanical energy is converted to electrical energy with the help of agenerator.

A wind turbine model consists of blades, a generator, a power electronic converter, and power grid. Blades are used to extract power from the wind. By operating the blades at optimal tip speed ratio, maximum amount of energy can be extracted from the variable speed wind turbine. The maximum power point tracking (MPPT) control of variable speed operation is used to achieve high efficiency in wind power systems. The MPPT control is operated using the machine side control system. The function of pitch angle control scheme is to regulate the pitch angle by keeping the output power at rated value even when the wind speed experiences gusts. The double fed induction generator is associated with $\mathrm{AC}$ to $\mathrm{AC}$ converter, where generator is directly grid connected through the stator windings, keeping into account the grid voltage and frequency fixed. While the rotor windings are fed by rotor side converter at variable frequency through slip rings. 


\section{MOTIVATION}

- Wind power is the most reliable and quick developing among the various renewable energy sources. Wind turbines can operate both in fixed as well as variable speed operation mode.

- For a fixed speed operation the generator is directly connected to grid whereas for variable speed the generator is controlled with the help of power electronic equipments. Therefore double fed induction generator plays a vital role by operating in grid as well as in stand alone mode.

- $\quad$ DFIG has attracted more attention due to its variable speed, reduced converter cost, less switching losses, higher energy efficiency and also for improved power quality. The controller in the double fed induction generator initially was implemented only with the help of a PI controller.

- However the problem associated with PI controller was the tuning of gains. Therefore PI controllers are difficult to control due to the tuning method. The problem was solved by changing the traditional PI controller with the improved Fuzzy PI controller.

- $\quad$ The advantage of using fuzzy control was to achieve a higher operation by the variation of the parameters. Fuzzy logic controller was superior over the conventional PI controller.

\section{MODEL OF WIND SPEED}

Wind power is basically in the form of kinetic energy moving above the earth ${ }^{\text {ee }}$ surface. Wind turbine blades collect the kinetic energy of air transforming into mechanical or electrical forms. The effectiveness of converting wind to other useful energy forms depend on the efficiency withwhich the rotor interacts with the wind flow. Kinetic energy contained in wind is given by:-

$$
E=\frac{1}{2} m v^{2}
$$

Where $m$ denotes the rate of flow of air and $v_{\circ}^{2}$ represents the speed of wind when undisturbed by anything. Taking into account a wind rotor of cross sectional area A exposed to the wind flow, equation (1) is given by:-

$$
E=\frac{1}{2} A V_{\circ} \rho v_{\circ}^{2}
$$

Where $A V$ denotes the volume flow and $A V \rho$ represents the mass flow. $V$ is the volume of air accessible to the rotor. Hence power, can be expressed as
From equation (3), we find that factors affecting the power available in the wind stream are the area of the wind turbine rotor, density, and the wind velocity. However the wind velocity effect is more due to its cubic relationship with the power.

\section{MAXIMUM AMOUNT OF ENERGY TO BE EXTRACTED}

Wind turbine cannot extract the power given in equation no. (3) completely from the wind. Only a section of its kinetic energy is transformed to the rotor, while the remaining air leaving the wind turbine is carried away. Therefore real power formed by a rotor will be decided according to the energy transferred that would take place from the wind speed to the rotor. This efficiency is defined as the power coefficient. Hence power coefficient of the rotor can be defined as the fraction of actual power developed by the rotor to the theoretical power available in the wind.

Where $P$

is the power developed by the turbine.

\section{TIP Speed Ratio $(\lambda)$}

The power delivered by a rotor at a definite wind speed depends on the relative velocity between the rotor tip and the wind speed. The fraction of the rotor blade tip speed and the unaffected wind velocity is expressed as tip speed ratio and is expressed as:-

$$
\text { TIP SPEED RATIO }(\lambda)=R v \omega=2 R n v \pi
$$

Where $\mathrm{n}$ denotes the rotational speed in rotation per minute, $R$ is the rotor radius, $\omega$ is the angular velocity and $v$ is the unaffected wind velocity.

This describes that the power extracted by the turbine increases as the wind speedincreases. Generated power reaches the rated power of the turbine, at the rated wind speed. But ifthe wind speed keeps on increasing, the output power also continues to rise and after a certain period of time the turbine has to be shut down when the speed exceeds a certain limit of the cut out wind speed. This is done for the safety purposes.

\section{Chapter Summary}

The characteristic is obtained by simulating the supply side converter with the help of fuzzy PI controllers. With the use of fuzzy Pi controllers the fluctuations in the curve aregreatly reduced. Therefore a faster and dynamic response is achieved with almost no overshootand faster settling time. By comparing both the results regarding the control of DC link voltagevariation, an observation is made, proving that the response of the system can be greatly improved by more precised use of fuzzy PI controllers.

$$
P=\rho A v(3)
$$




\section{CONCLUSION AND SCOPE OF FUTURE WORK}

\subsection{Conclusion}

Modeling of the wind turbine is done so as to control the amount of power extracted from the wind.we have seen that with the increase in the velocity of the wind, thecapacity to extract power also increases. However, if the velocity of wind will keep onincreasing, the output power will also increase and if the wind speed continues to rise further acontrol system will be required to limit the output power. This is done by modeling of the turbineblades to ensure a safe operating region for a wind turbine. A DFIG is used instead of synchronous generator due to its nature of variable speed and improved amount of power quality and also it reduces the cost of the converter used. The modeling of the Double fed inductiongenerator is done from the abc variables to the $\mathrm{dq}$ axis variables, so as to reduce the number ofvariables and also to reduce the complexity of the model.Proportional integral controller action the equivalent circuit diagram for the separate $d$ and $q$ axis. A thoroughreview is done relating to modeling and control of the grid side using vector control strategy. The vector control strategy that is implemented for the grid side control ensures a decouplingstrategy of the stator side. A simulation model is represented in Fig 4.1 proving that the dc linkvoltage is maintained constant using a PI controller. A PLL control technique block was used tomeasure the phase angle. In the traditional PI control, two loops namely current control andvoltage control loop have been implemented.Fuzzy PI controller action

However, a new improved and a convenient strategy, fuzzy PI technique has been further developed to control the dc link voltage. In the case of fuzzy PI control, error has been taken asthe input value and the output showing different $\mathrm{Kc}$ and $\mathrm{Kt}$ values has been listed.

Different $\mathrm{Kc}$ and $\mathrm{Kt}$ for the current control and voltage control loop have been noted. A comparison plot has been done between the simple use of PI and fuzzy PI, to ensure the bestamong the controller. The result showed the fuzzy controller was superior in performance ascompared to the traditional PI controller.

\subsection{Scope of Future Work}

I. To implement fuzzy PI concept in the machine side converter to achieve betterperformance results.

II. Extraction of the maximum power from the wind using MPPT algorithm.

III. Try to simulate the fuzzy PI controller using improved membership function and rules toobtain a better stability of the dc link voltage.

\section{REFERENCES}

[1]. R. Pena, J. C. Clare, and G. M. Asher, “A doubly fed induction generator using back-tobackPWM converters and its application to variable-speed wind-energy generation,"Proc. Inst. Elect. Eng., vol.143, no. 5, pp. 231241, May 1996.

[2]. J. Yao, H. Li, Y. Liao, and Z. Chen, "An Improved Control Strategy of Limiting the DCLink Voltage Fluctuation for a Doubly Fed Induction Wind Generator," PowerElectronics, IEEE Trans. Power Electron , vol.23, no.3, pp.1205 - 1213, May 2008.

[3]. L. Fan, H. Yin, and Z. Miao, " A novel control scheme for DFIG based wind energy systems under unbalanced grid condition", Electric Power Systems Research, Volume 81,Issue 2, pp: 254-262, February 2011.

[4]. Shenghu Li, "Power Flow Modeling to Doubly-Fed Induction Generators (DFIGs) Under Power Regulation," Power Systems, IEEE Transactions on, Volume 28, no.3, pp.3292-3301, Aug. 2013. 